\title{
Una relación de amor-rechazo: Elías Nandino y Contemporáneos
}

\author{
Lilia Solórzano Esqueda \\ Universidad de Guanajuato
}

Resumen

Este artículo intenta mostrar el tono de las relaciones personales, las afinidades de espíritu y las distancias entre algunos miembros destacados del grupo Contemporáneos y el poeta Elías Nandino. Se hace un registro de sus primeros contactos y se da cuenta de la proximidad que alcanzó la amistad entre el escritor jalisciense y Xavier Villaurrutia, particularmente; así como los puntos de encuentro y de disenso en ambas poéticas.

Palabras clave: Contemporáneos, Elías Nandino, poética nandiniana, experiencia vital, almendra del mundo.

\section{Abstract}

This article tries to show the tone of personal relationships, affinities of spirit and the distances between some prominent members of the group Contemporáneos and the poet Elias Nandino. A record of his first contacts are made and realizes the proximity that reached the friendship between the Jalisco writer and Xavier Villaurrutia, particularly; as well as meeting and dissent in both poetic points. 
Keywords: Contemporáneos, Elías Nandino, Nandino’s poetics, vital experience, almond of the world.

A fines de 1922 Elías Nandino Vallarta llegó a la Ciudad de Ménía de Guadalajara, de haber cursado un año en la misma carrera, en el Colegio Figueroa. Ahí había fundado con sus compañeros de escuela la revista La sombra de Nervo, a la que poco después modificaron el nombre para llamarla Bohemia. Los dos títulos dan clara idea de los autores y actitudes tutelares que guiaban las inquietudes poéticas de varios jóvenes que aún no habían cumplido la veintena, con los pies todavía puestos en las orillas de un decimonónico siglo cuyas flores seguían aromando, aunque un poco marchitamente, el olfato artístico incipiente de la centuria que iniciaba. Así como Ramón López Velarde anota en "Tenías un rebozo de seda..." publicado en el poemario La sangre devota, en 1916, para referirse a sus años de inocencia, también ellos estaban "sin Baudelaire, sin rima y sin olfato” (López Velarde, 1986: 85).

Nandino contaba con 22 años en esa época y un ansia desbocada por comerse el mundo a puños. Al poco tiempo y junto con su amigo Roberto Rivera, compañero suyo desde Guadalajara, publicaron la revista Allis Vivere que tuvo una aceptable acogida estudiantil y por la que otro condiscípulo, Delfino Ramírez, les propuso presentarlos con Xavier Villaurrutia y Salvador Novo. Para entonces, Villaurrutia y Novo compartían un pequeño estudio en la calle de Brasil, cerca del templo de Santo Domingo. Ahí fue donde por primera vez se encontraron los noveles poetas. "Delfino tocó la puerta de unos cuartitos - como celdas- que había en el cuarto piso. Abrió un señor alto, delgado, como víbora parada, un poco torcido y con el cabello alborotado. Era nada menos que Salvador Novo" (Nandino, 2000: 59). Villaurrutia se sumó a las presentaciones, platicaron los cuatro sobre sus intereses literarios, que resultaron de una afinidad pasmosa y, pasado un rato, Nan- 
dino y él se retiraron a la otra habitación, la que correspondía al poeta de Reflejos, donde a decir del migrante jalisciense "estuvimos conversando de nuestras preferencias entre los escritores, especialmente los poetas. Coincidimos en Enrique González Martínez y Juan Ramón Jiménez, poeta español. Indudablemente que hubo una simpatía mutua y en ese momento nació una de las amistades más grandes y hondas que tuve en la vida" (60). Desde ese día se encontraron consuetudinariamente, hubo una "una conexión casi diaria para ir a cenar, a teatros, a cines y a vagar por las calles" (60). De inmediato a Nandino le agradó la personalidad de Villaurrutia: "era discreto, educado y con cierta luminosidad de inteligencia" (59), y a partir de ahí el joven coculense, aspirante a médico y poeta, se enlazó con las dos figuras medulares de lo que años después sería conocido como el grupo Contemporáneos; o también podríamos decir que comenzó una relación con los dos integrantes de lo que el mismo Salvador Novo llamó "generación bicápite". Nandino hace una separación, en su autobiografía, de dos bandos disgregados - o conjuntados, como se prefiera ver- por afinidades vitales y por las apetencias sexuales:

Al poco tiempo se formó el famoso "Grupo sin grupo", cuando Xavier y Salvador conocieron a Jorge Cuesta y Gilberto Owen y se juntaron con José Gorostiza y Jaime Torres Bodet. A Enrique González Rojo casi no lo conocíamos porque era diplomático y casi siempre estaba fuera, en España o en Chile. Roberto y yo no asistíamos del todo porque teníamos nuestras clases, pero nos dábamos cita especialmente con Xavier. [...] Después, cuando ya nos juntábamos todos, pasaba lo que con el agua y el aceite: tratándonos no nos mezclábamos. De un lado, Gilberto Owen, José Gorostiza, Bernardo Ortiz de Montellano y el reprimido Jaime Torres Bodet, de quienes conseguí la amistad y conversaciones literarias. Del otro lado, los marcados por la mano de Dios y Jorge 
Cuesta, quien era bisexual, de los que conseguí el prestigio y el desprestigio (60-61).

En su relato el poeta jalisciense destaca más bien vivencias de corte intimista, no hace propiamente retratos intelectuales, digamos que el tono se orienta hacia un tipo de escritura más personal, pero nunca llega a parangonarse con el estilo exhibicionista del que Novo hace gala en La estatua de sal. Nos podemos enterar, por su testimonio, de que se iban de juerga al “'Salón México', a la 'Playa Azul', al 'Tenampa' y a todos los sitios donde había vino, canto, golfos y oportunidades" (60-61); pero también de que para las conversaciones literarias y de contenido intelectual se reunían "en un café, en restoranes, en los cuartos de estudio que ya tenía[n] en Brasil núm. 41, en [su] consultorio, que era muy amplio, o en el estudio de Roberto Montenegro, que estaba junto al templo de San Pedro y San Pablo. También muchas veces [se] reunía[n] en casa de Agustín Lazo, que había llegado de París y participaba con mucho entusiasmo y alegría” (60-61). De Contemporáneos, Nandino establece la siguiente nómina:

[...] lo componían estrictamente Villaurrutia, Novo, Jorge Cuesta, Gilberto Owen, José Gorostiza, Jaime Torres Bodet, Bernardo Ortiz de Montellano y Enrique González Rojo; agregados a ellos en continuo trato Salazar Mallén, yo, Agustín Lazo, quien fue parte de la inteligencia medular que ellos aprovecharon, como hicieron con Octavio Barreda, hombre de muy buen humor que, como diplomático, los conectaba más con todas las literaturas de Europa y podía enviarles colaboraciones o recomendaciones de libros y quien, cuando regresó a radicar a México, tuvo el mérito de publicar la gaceta Letras de México y la revista El Hijo Pródigo. Un gran elemento para la cultura literaria de México. [...] también se agregó al grupo Carlos Pellicer, poeta que hizo su fama en Colombia y que vino a completarla entre nosotros. Los "Contemporáneos" hacían un círculo cerrado y querían llegar a puestos 
diplomáticos o vivir de las letras como empleados públicos para conquistar la fama. De ahí su egoísmo. Trabajaban para ellos mismos y los otros tenían que trabajar para ellos (61-62).

Se advierte cómo el poeta de Nocturna palabra se identifica sólo como "agregado" del "grupo sin grupo" como los autonombró Xavier Villaurrutia, y se refiere a sus integrantes con la tercera persona del plural, en un franco alejamiento. Casi toda su vida, Nandino insistirá, por un lado, que formó parte de esta colectividad por las afinidades de espíritu indagador, inquisitivo; por su búsqueda de nuevas formas y maneras de decir la literatura; por su ingenio, su inteligencia siempre a flor de piel, su franca inconformidad al anquilosamiento, la lectura constante de nuevos autores, en fin, por esos motivos que Villaurrutia comentó a Edmundo Valadés en una carta:

El grupo en el que usted me cuenta y en el que yo mismo me incluyo se formó casi involuntariamente por afinidades secretas y por diferencias más que por semejanzas. [...] unas soledades que se juntan. Medite usted en el significado de estas denominaciones hechas sin programa alguno de política literaria y como a pesar nuestro. ¿Qué es lo que ata estas soledades? ¿Qué es lo que agrupa un momento a unos cuantos seres para separarlos enseguida? Desde luego la semejanza de nuestras edades, de nuestros gustos más generales, de nuestra cultura preservada en momentos en que nadie cree necesitarla para nutrir sus íntimas vetas. Además, nuestro deseo tácito de no hacer trampas, de apresurarnos lentamente, de no caer en el éxito fácil, de no cambiar nuestra personal inquietud por un plato de comodidades, de falsa autoridad, de auténtica fortuna. [...] La libertad es [...], aunque pueda parecer mentira, el lazo que, al mismo tiempo, nos une y nos separa (Villaurrutia en Sheridan, 2003: 13-14). 
Aunque también es cierto que probablemente Nandino no estuviera muy convencido de la honestidad de todo lo que afirma el poeta de Nostalgia de la muerte, porque en repetidas ocasiones ha aseverado lo que se anota líneas arriba, el que eran egoístas y querían costearse su fama literaria a expensas del servicio público. Le chocaba un poco su énfasis en voltear los ojos hacia el extranjero y perder el piso con su país, así como la exacerbada gana de lograr una poesía intelectualizada, sin rastro de emoción. En una entrevista, a los 89 años de edad, incluso llega a decir que

los Contemporáneos se aprovecharon del impulso poético de López Velarde y aportaron una novedad. El público ya se había hastiado de un romanticismo ya gastado y de un modernismo exageradamente usado; con este panorama, los Contemporáneos empiezan a escribir otras cosas y tienen éxito, porque partieron de la retórica y, para mí, la poesía parte de las verdades y de una vida que es vivida con experiencias. Por eso la poesía de ellos se fue haciendo hueca con el tiempo y ha quedado volando (Bustamante, 2009: 163).

En estas palabras quedan contenidos por lo menos dos principios de la poética nandiniana y una actitud que nunca lo abandonó: los primeros son buscar a toda costa una verdad contenida en los propios versos que se forja con el esfuerzo y conocimiento del lenguaje sí, pero que no es sólo eso. Las palabras contienen una gran porción de espíritu y de todo lo que conforma al autor: tristezas, alegrías, concepciones de la vida, frustraciones, impedimentos reales o imaginados; y de aquí se desprende que la poesía sea considerada resultado también de la existencia misma. Eso le da densidad y humanidad, de otra manera es solamente retórica; es decir, palabrería inocua. Como los "hombres huecos" del poema de T. S. Eliot. La actitud a la que apela Nandino es la de la honradez, en parte porque un hombre no puede ir por el mundo en una especie 
de esquizofrenia con sus pensamientos y sus creaciones por un lado y su existencia por otro; $y$ en parte porque cree firmemente en una moral en la creación artística. En una entrevista diferente comenta:

Nunca les tuve confianza a los Contemporáneos. Sentía que lo que ellos escribían era pura simulación. Yo tenía otro concepto, por eso siempre me guardaba mis poemas, mis libros; sin que ellos supieran, los publicaba. Nunca me daban el visto bueno, eran muy pesimistas. Decían, si algo no les gustaba, que me iba a quemar. Lo raro era que, aún con esos criterios, mis libros triunfaban siempre. Por ello les tenía desconfianza. Era típico que me trataran de esa manera. No obstante, había una afinidad entre Villaurrutia, Novo, Cuesta y yo: las ganas de vivir la vida. Los otros escribían con la intención de ganarse puestos diplomáticos: Torres Bodet, por ejemplo (Bustamante, 2009: 120).

Historiógrafos y críticos literarios no se han puesto de acuerdo en definir una única nómina para esa "cinta de Moebius" — como los denomina Guillermo Sheridan- que fue Contemporáneos, y a lo largo de los años ésta engrosa o adelgaza según los parámetros y criterios de quien la enuncia. Jorge Cuesta, a un ańo de desaparecida la revista que da nombre al grupo, en 1932, contabiliza en su recuento a Carlos Pellicer, Enrique González Rojo, Bernardo Ortiz de Montellano, José Gorostiza, Jaime Torres Bodet, Xavier Villaurrutia, Salvador Novo, Gilberto Owen, Celestino Gorostiza y Rubén Salazar Mallén (Cfr. Sheridan, 1985: 12). Habría que precisar que los incluidos en la tercera parte de la Antología de la poesía mexicana moderna, firmada por él mismo, son casi todos los anteriores excepto los dos últimos: Celestino Gorostiza y Salazar Mallén. El investigador estadunidense Merlin H. Forster en su ensayo Los Contemporáneos 1920-1932. Perfil de un experimento vanguardista mexicano los ve como "un círculo reducido de amigos que entre los años 1920 y 1932 colaboraron en una serie de tra- 
bajos literarios", e identifica "tres subgrupos sucesivos": el primero formado por Ortiz de Montellano, González Rojo, Gorostiza y Torres Bodet; el segundo, por Villaurrutia y Novo; y el tercero, por Owen y Cuesta. Este es un núcleo medular, según su apreciación. Después sitúa a Carlos Pellicer, Octavio G. Barreda, Elías Nandino y Rubén Salazar Mallén como escritores "que conocían a los del grupo y a veces contribuían a las revistas, pero nunca se unieron al cenáculo"; y a Martín Gómez Palacio, Enrique Asúnsolo, Salomón de la Selva y Samuel Ramos los ubica "más lejos aún del grupo" (Forster, 1964: 7-8).

José Luis Martínez en su Literatura mexicana siglo XX. 19101949, reúne en esta generación, advirtiendo que no era "inicialmente homogénea”, a Carlos Pellicer —el "menos 'contemporáneo' de los 'contemporáneos'”-, Bernardo Ortiz de Montellano, José Gorostiza, Jaime Torres Bodet — “ansioso de coger el fruto de cada estación”-, Xavier Villaurrutia, Salvador Novo, como los centrales; y ensancha demasiado el círculo anotando como parte del grupo o con obra publicada en los mismos años a Enrique González Rojo, Enrique Asúnsolo, Salomón de la Selva, Agustín Lazo, Gilberto Owen, Octavio G. Barreda, Jorge Cuesta, Carlos Díaz Dufoo Jr., Rubén Salazar Mallén, Renato Leduc, Bernardo J. Gastélum, Eduardo Luquín, Carlos Luquín, Anselmo Mena, Enrique Munguía, Eduardo Villaseñor, Samuel Ramos, Elías Nandino, José Martínez Sotomayor, Emanuel Palacios, Alfonso Gutiérrez Hermosillo, Genaro Estrada, Celestino Gorostiza y Rodolfo Usigli (Martínez, 1990: 44 y ss.).

Para Guillermo Sheridan la lista de los Contemporáneos es "elástica" debido a su "carencia de un programa o de directrices programáticas estrictas" (2003: 17). Al investigador mexicano no le interesa, para su estudio Los Contemporáneos ayer, la nómina expandida que incluye por diversas razones "invariablemente pertinentes y considerables, a Carlos Pellicer, Elías Nandino, Genaro 
Estrada, Enrique Munguía Jr., Celestino Gorostiza, Rubén Salazar Mallén, Ermilo Abreu Gómez — estos últimos, eventualmente habrían de convertirse en enemigos de tiempo completo de los demás-, Ignacio Barajas Lozano, Anselmo Mena y muchos más" (17). Él considerará el mismo núcleo central propuesto por Merlin H. Forster y E. J. Mullen, descrito líneas arriba. Es decir, para lo que nos ocupa aquí: Elías Nandino no forma parte de Contemporáneos, salvo en sus versiones más ampliadas.

El poeta, por su parte, aduce que no escribió nunca en la revista ni participó del proyecto porque para 1928 se fue a Estados Unidos a realizar una estancia necesaria en la culminación de su tesis sobre medicina y que cuando regresó a México, Contemporáneos ya había concluido. En general, piensa que el que no haya "militado", por llamarlo de algún modo, en el grupo fue debido a la falta de tiempo, a la exigencia de partirse en dos: por un lado, su profesión de médico cirujano y, por la otra, su vocación de poeta. A una le dedicaba el día y a la otra, las noches. También es cierto que lo mejor de la obra poética de Nandino no se dio en esa época. La de él ha sido una producción reposada, que fue madurando lentamente y prodigó los mejores frutos andando el tiempo, incluso cuando su mejor amigo y cómplice, Villaurrutia, ya había fallecido. El poema que escribe a propósito de la muerte de Xavier incluido en el poemario de 1955, Nocturna suma, es una muestra:

\footnotetext{
Si hubieras sido tú lo que en sombras, anoche,

bajó por la escalera del silencio

y se posó a mi lado,

para crear el cauce de acentos en vacío que, me imagino, será el lenguaje de los muertos.

Si hubieras sido tú, de verdad, la nube sola que detuvo su viaje debajo de mis sábanas y se amoldó a mi piel
} 
de una manera leve, brisa, aroma, casi contacto angelical, sońado... Si hubieras sido tú lo que apartando la quietud oscura se apareció, tal como si fuera tu dibujo espiritual que quiso convencerme de que sigues, sin cuerpo, viviendo en la otra vida. Si hubieras sido tú la voz callada que se infiltró en la voz de mi conciencia, buscando incorporarte en la palabra surgida de tu muerte, por mis labios. Si hubieras sido tú lo que en mi sueño descendió como bruma, poco a poco, y me fue encarcelando en una vaga túnica de vuelo fallecido... Si hubieras sido tú la llama llama que inquemante pasó por mi desvelo sin conmover el lago del azoro, igual que en el espejo se sumerge la imagen, sin herirle el límpido frescor de tu epidermis, si hubieras sido tú...

Pero nuestros sentidos no pueden identificar las ánimas. Los muertos, si es que vuelven, han perdido todo lo que pudiera darnos el goce de reconocerlos.

¿Quién más pudo venir a visitarme? Recuerdo que, contigo solamente, muchas veces hablé de la zozobra en que el constante asedio de la muerte nos tiene sepultados, y hablábamos los dos adivinando, 
haciendo conjeturas,

ajustando preguntas, inventando respuestas,

para quedar sumidos en derrota,

muriendo en vida por pensar la muerte.

Ahora tú ya sabes descifrar el misterio

porque estás en su seno; pero yo no sé nada...

En esta incertidumbre secretamente pienso

que si no fuiste tú lo que en las sombras, anoche,

bajó por la escalera del silencio

y se posó a mi lado,

entonces quizá fue

una visita de mi propia muerte

(Nandino: 1980: 60-62).

La repetición anafórica de la frase "Si hubieras sido tú" es la medula de la que se desprende la construcción del poema, como cántico, como monodia casi elegiaca. Una oración fúnebre poco ortodoxa, que paradójicamente no tiene las características del rezo excepto por el tono y el asunto en el que la muerte es central. Una muerte con la suavidad de las nubes, dotada de la sustancia de lo angelical, nunca de lo violento o lo corrompido; un "dibujo espiritual" pero tangible, sensible en la piel como el roce de una tela ligera, una "voz callada" que se percibe en un oído especial desarrollado por la conciencia y no por el común órgano de la oreja, por donde nos entran los sonidos de este mundo. La experiencia del contacto con lo sobrenatural en este poema está muy lejos de lo terrorífico. La muerte provoca una sensación de "túnica de vuelo fallecido", no tiene la gravidez o el peso con que normalmente la asociamos. Esa presencia nos dirige hacia una pregunta, inquiere al pensamiento sobre lo que puede significar la muerte, más que conducirnos o hablarnos de un estado emocional. La voz poética no es doliente, no llora una pérdida sino interroga por una condición metafísica. 
El poeta jalisciense retoma en este poema temas fundamentales para ambos: la noche, el sueńo, el silencio, la muerte, la duda; inquietudes y misterios compartidos en largas noches de desvelo en que Nandino tenía guardia en el Hospital Juárez, y al que acudía Villaurrutia infinidad de veces para compartir lecturas propias y de otros autores. Fue él quien le ofreció presentar Ecos, impreso en 1934. En esas palabras elogiosas, las únicas por lo demás que le dedicaría Villaurrutia a la poesía de Nandino, se entrevé el excelente augurio del agudo crítico y del buen amigo, pese a considerarlo verso acerbo todavía. Entre otras cosas le dice:

[...] Este hombre que arde y se consume en los ejercicios más diversos; que halla equilibrios momentáneos de la razón y del instinto, pero que se distrae y da con su cuerpo en la red que él mismo ha tendido a sus pies, pero que se levanta y vuelve a empezar... Este hombre que, en una palabra, vive y, sin tener una conciencia lúcida de su deseo, quiere verse vivir, se llama ahora Elías Nandino.

Yo lo he visto sostener, alternativamente, el lápiz del escritor y el bisturí del cirujano; escribir y operar; escribir con fiebre y operar con frialdad.

[...] ¡Ya lo imagino, el día más pensado, desprenderse de sí mismo y con precauciones infinitas, lúcido y frío, auscultar su propio tronco ardiente, seguir las intermitencias de su corazón, poner al descubierto las capas profundas de la tierra del cuerpo y explorar las antiguas cavernas del pecho para extraer, de los complicados repliegues de la red de los nervios, los ligeros pájaros y los seres marinos que el hombre ha ido ocultando en el hombre! (Villaurrutia en Nandino, 1982: 8-9)

Después de esto, el silencio. No hay — hasta donde se conoceninguna otra muestra de atención hacia la producción nandiniana. Será porque lo esencial de este escritor vino después de 1950. Ya no le alcanzó vida al capitán de Ulises para conocer y disfrutar Trián- 
gulo de silencios (1950), Nocturna suma (1955) y menos Nocturna palabra (1960). A fines de 1950, un amigo de Carlos Pellicer, el ingeniero Félix Jorge Martínez, le invitó a Córdoba, Veracruz, para que instalara un nacimiento; al poeta tabasqueño se le adhirieron al proyecto del viaje Elías Nandino, Roberto Montenegro y otros más. Villaurrutia, días antes de partir, visitó en su consultorio a Nandino para comentarle que no iría. Ambos discutieron acremente. El primero se encontraba en un estado de ánimo alterado y tan nervioso que dio unos golpes con los nudillos en la pared sin explicar mucho. Nandino afirma en su autobiografía saber la razón y la atribuye a problemas vinculados con el lado amoroso de la vida, asuntos del corazón. Ésa fue su despedida. El día 26 de diciembre vio en un periódico cordobés el titular: "Súbitamente murió Xavier Villaurrutia":

Sentí que me partieron longitudinalmente; desde ese momento me sentí incompleto. Corrí a darles la noticia. Carlos lloró, Montenegro lloró. Fue una verdadera tragedia. Inmediatamente hablamos a su casa y nos contestó Teresa, su hermana. Me reprochó que yo no hubiera estado allí y, después de contarnos la situación, me dijo que ya lo habían enterrado. Comprendimos que toda prisa era inútil. Yo, en mis adentros, reproducía la escena final del consultorio y no me cansaba de pensar que eso había sido un suicidio (Nandino, 2000: 67-68).

Jorge Cuesta murió muy pronto, en 1942; Gilberto Owen, en 1952; sin menciones a la obra de Nandino, excepto por una emotiva felicitación en una carta de Owen enviada desde Filadelfia, en noviembre de 1948. De José Gorostiza y Salvador Novo, ni hablar.

Nandino mostró a lo largo de su vida, y cada que el asunto salía a la palestra en las entrevistas -es decir, casi siempre-, un poco de resentimiento a los del grupo con los que tenía un trato más constante; lo cual es hasta cierto punto muy natural porque con 
ellos convivía, había establecido un lazo de amistad que ciertos gestos, actitudes y hechos lastimaban. Con el resto de los integrantes de este "archipiélago de soledades", como los motejó José Gorostiza, el vínculo era más desapasionado, más puramente literario y convencional. No obstante, si creemos en su testimonio, Muerte sin fin, de Gorostiza, se leyó por primera vez en su consultorio; lo mismo que la primicia de "Nocturno rosa", de su queridísimo Villaurrutia. Lo que sí es demostrable es que Notas sobre poesía, de Gorostiza, se publicó en la revista Estaciones.

A Salvador Novo, después de un tiempo de relación, francamente no le guardaba mucha simpatía y puso mayor distancia, pese a seguir algunas de sus ocurrencias y considerar que sus primeros libros XX poemas y el relato de viaje Return Ticket, fueron valiosos en la medida de su descubrimiento y asimilación de las poéticas plásticas norteamericanas de la New Poetry. Declara, por ejemplo: "Yo aborrecía a Novo porque una vez habló muy mal de Villaurrutia, cosas tremendas. Y me dijo algo que me ofendió mucho. [...] 'Yo no sé por qué quieres tanto a Jorge Cuesta y a Xavier. Mira - dice - yo te digo en confianza: Jorge Cuesta le dijo un día a Xavier: Tú que eres tan amigo de Elías aconséjale que deje la poesía porque no es para él", y añade más adelante: "Ellos eran muy frívolos para juzgar; nunca me comprendieron, y yo nunca tuve - como ellos- empleos en el gobierno. A mí nadie me ayudó. [...]. Yo los ataqué después de muertos, pero ellos me atacaron en vida; me trataban como la cenicienta" (Bustamante, 2009: 89).

De Jorge Cuesta reconoce su poema "Canto a un dios mineral" como "muy bueno", pero después le fustiga, "como poeta no vale nada. Sus sonetos son duros, forzados y críticos. Y su crítica literaria era dura y a veces injusta, porque condenaba con facilidad y a los amigos los perdonaba con esa misma facilidad. Lo cierto es que el grupo de 'Contemporáneos' fue una especie de club en el que se trataban como en el cuento del periquito rey, con esa frase, 
y todos eran reyes" (2000: 75). No obstante, en un artículo publicado como homenaje en Jorge Cuesta. Poemas, ensayos y testimonios, le dedica palabras de mucho encomio:

No era criatura humana ni inhumana; más bien un rencor pensante que pisoteaba a sabiendas la vida. [...] Estaba hecho como de dos mitades disímbolas; una de hombre semivendado, otra, de auténtico demonio que escudriñaba todo, que veía todo, que lo sabía todo. [...]

Hablaba en un solo tono, con palabras secas, amargas, desnudas. [...] Más que hombre parecía una balanza de precisión. Cuando hacía crítica, disecaba con avidez quirúrgica y se deleitaba en sangrar y conocer la más escondida fibra de la obra. Odiaba la inspiración por considerar que era un estorbo para realizar la verdadera obra de Arte, que él concebía como el resultado de un acto de conciencia. [...] Afirmaba que la Poesía era un problema de multiplicación que el lector debía resolver.

[...] su palabra no era ni detonante ni furiosa, tampoco saturada de veneno o erizada de envidia, no; pero era exacta y desnuda, penetrante y certera, cruel por su verdad y constructiva por la disección que producía. [...]

Oculto bajo su exterior helado, existía el hombre sencillo, tierno, generoso; el que a veces olvidaba su conciencia dictatorial y con lenguaje claro, natural, expresaba sus sentimientos o dibujaba sus recuerdos.

[...] Siempre estaba en lucha contra [...] las viejas escuelas literarias que tenían en estado de atrofia nuestras letras (Schneider, 1981: 178-180).

Para Gilberto Owen sólo tuvo expresiones de aprecio. Recuerda en su texto biográfico: "fue un hombre limpio y un amigo insuperable. Era amable y no hablaba mal de nadie". Líneas después enfatiza: "sus poemas, especialmente los primeros, con intensa influencia de Juan Ramón Jiménez, son verdaderas joyas" (Nandino, 
2000: 77). Lo recuerda con mucho cariño y dulzura, aunque sólo se conocen tres cartas a Nandino del sinaloense cuando estaba en Estados Unidos; una, en el solsticio de invierno de 1948, y dos en 1951; una en Semana Santa y la otra en noviembre. También hizo sendas menciones al poeta jalisciense en dos cartas enviadas en agosto de 1949 y en julio de 1950 a Josefina Procopio, su compañera que se encontraba en México. De lo que se conoce, antes de 1948 y desde su partida al extranjero a mediados de 1928, su gran corresponsal del grupo fue únicamente Xavier Villaurrutia. Es de justicia aclarar que las misivas de Owen a Nandino son poquísimas, pero son de miel. Le cuenta que le dedicará un canto especial el 24 de diciembre, la víspera de Navidad, y ańade: "Tu libro me ha llenado de una gran alegría, es la parte más pura y más hermosa de tu obra. Lo he leído temblorosamente. Me he olvidado por completo de tu amistad, que me brilla en el corazón, para leerlo, y tu amistad se me ha metido por la cabeza y por los nervios. Me siento emocionado, Elías. [...] ¿Dónde estás, si no en mi admiración intelectual y en mi amor de hermano?” (Owen, 1979: 290)

Elías Nandino rechazó casi desde el comienzo de su relación con este grupo de poetas ese afán por separarse de la realidad de su país, un ansia de derribar fronteras y compenetrarse con el mundo más allá de los límites circunscritos por la ideología de la Revolución Mexicana; si bien, un mundo reducido a Estados Unidos y Francia principalmente. Así como para sus abuelos, los decadentistas y modernistas de fin del siglo XIX y comienzos del XX, el medio y lejano Oriente, lo mismo que los simbolistas franceses jugaron un papel central en sus gustos y experiencia estética. Un descendiente en línea directa de aquel simbolismo fue figura tutelar para los mexicanos: el francés Paul Valéry. Gilberto Owen recuerda cómo Cuesta

me arrancó a estocadas de lógica poética de la raíz juanrramoniana de que mi adolescencia no se avergonzaba, y acosándome 
en un rincón con Gide y Valéry —que a su vez fueron sus dos influencias mayores - me obligó a reconocer que lo mexicano de la poesía española escrita en México está precisamente en su desarraigo de lo mexicano, en su universalidad, "en su preferencia de las normas universales sobre las normas particulares”, y me enseñó a buscar esas normas en el clasicismo francés (1979: 245)

Nandino no adoptó nunca lo que Owen bautizó como "Ley de Cuesta”, esa ley "que nos exige ordenar la emoción, reprimirla hasta el grado en que parezca haber sido suprimida, simular que no existe, disimular su presencia inevitable, para que el ejercicio poético parezca un mero juego de sombras dentro de una campana neumática, contemplando con los razonadores ojos de la lógica no de la lógica discursiva, naturalmente, sino de la poética” (1979: 243). Por el contrario, en Nandino la poesía sucede de la experiencia vital; la inspiración noctámbula que despierta sus sentidos cede lugar privilegiado a la pasión creadora, y él no se preocupa de que corra libremente, no intenta sujetarla con bridas manejadas por un exceso de raciocinio o contención intelectual. La poesía pura no le interesa. No siendo "vanguardista" ni "purista", tampoco es "mexicanista" y menos "nacionalista". Sólo es un poeta. Y sin embargo, decir que la poesía sucede, lleva implícita la connotación de la no intencionalidad. Es decir que la voluntad permanece al margen. No totalmente, pero sí una porción de ella. No totalmente porque si así fuera estaríamos abordando los objetos poéticos surgidos del automatismo surrealista donde justamente la pretensión fundamental era prescindir de la voluntad razonante y dejar paso al libre flujo de la inconsciencia, como sucede en el sueño. En Nandino hay una fuerza interior, una voluntad que lo impele a escribir todas las noches, después de las arduas jornadas que le exige su trabajo profesional. Cura enfermos por el día y cura su alma por la noche.

Por supuesto que el poeta jalisciense leyó lo mismo que sus compañeros: Baudelaire, Nerval, Mallarmé, Valéry, Supervielle, 
Gide, Cocteau, Freud, sus queridísimos Bécquer y Juan Ramón Jiménez, lo mismo que San Juan de la Cruz, Góngora, Garcilaso, Quevedo, Sor Juana, Othón, Tablada, Nervo, Díaz Mirón, López Velarde, Rubén Darío y José Asunción Silva. Y la lista se alarga. Pero de entre todos ellos, la poesía de Nandino se inclina más hacia los autores de un tono íntimo, crepuscular y natural, con menos peso del artificio y más de la experiencia vital. Sus poemas no son construcciones recargadas de ornamento formal, ni son ejemplo de los "estados intelectuales" pregonados por Valéry en su Poesía y pensamiento abstracto que abrirá la puerta de par en par a la poesía pura.

\section{Xavier Villaurrutia: una afinidad contrastada}

De entre todos los Contemporáneos, indudablemente que Nandino tenía una predilección hacia el poeta citadino de los nocturnos. Cualquier desavenencia que pudo haber surgido entre ambos la pasó por alto, generalmente. Siempre aseguró que su amistad y consideración superó todas las zonas de sombra:

Era amable, educado y discreto; [...] tenía excelente conversación; hábil para ofender sin hacer herida e inteligente para defenderse. Siempre se estuvo cultivando, leyendo tanto en español como en inglés y francés. Con la intimidad de Agustín Lazo aprendió a traducir perfectamente el italiano. Puede decirse que su amistad con Agustín, quien era muy preparado, vino a completar su cultura y le dio la media sabiduría europea en teatro y en pintura. [...] En lo particular yo lo admiraba. Creo que aprendí mucho de él, la crítica y la autocrítica; me infiltró el rigor para mi escritura. En lectura, seguí sus pasos y casi siempre discutíamos los mismos libros, y juntos leíamos a psicoanalistas. Y creo que yo influí en él desde el punto de vista humano [...] Me acompañaba a visitar a mis enfermos, y yo me daba cuenta cuando a los muy pobres 
les deslizaba algunas monedas debajo de la almohada. Muchas veces estuvo en mis guardias en el Hospital Juárez y presenció mis delicadas operaciones y hasta los infortunados resultados. [...] En honor a la verdad, fue el amigo con quien más congenié y a quien más quise (Nandino, 2000: 65-66).

Se veían casi todos los días, solos o acompañados, en comidas y cenas. De hecho, muchos años después de entablada esta amistad, en 1937, Octavio Paz recuerda la primera comida a la que estuvo invitado, conducido por Villaurrutia y Cuesta, para conocer a todos los intelectuales del grupo. Era su "ceremonia de iniciación":

Un taxi nos llevó a un restaurante que estaba frente a una de las entradas del Bosque de Chapultepec, cerca del mercado de las flores: El Cisne. Recuerdo muy bien a los asistentes: Ortiz de Montellano, José y Celestino Gorostiza, Samuel Ramos, Octavio G. Barreda, Jaime Torres Bodet, Enrique González Rojo, Elías Nandino y el Abate Mendoza. Tres ausentes: Pellicer, Novo y Owen. (Este último vivía en Colombia.). Se habló de las opuestas ideas de Goethe y Valéry acerca de la traducción poética, pero, sobre todo, se habló de Gide, el comunismo y los escritores. Eran los días de la guerra civil en España. Todos ellos eran partidarios de la República; todos, también, estaban en contra del engagement de los escritores y aborrecían el "realismo socialista", proclamado en esos años como doctrina estética de los comunistas (Paz, 2003: 13).

La compañía Nandino-Villaurrutia era muy cercana, muy íntima. En una entrevista con Sandro Cohen, el primero le platicaba que hasta cierto parecido en la fisonomía se desarrolló entre ambos, "Cuando tú vives y andas con una gente todo el tiempo, hay un contagio no sólo espiritual, sino también mental y corpóreo. Te vas haciendo a la forma de la otra persona. Nadie concebía, por ejemplo, que Elías Nandino fuera a una fiesta sin Xavier; casi siempre andábamos juntos". Desde 1922 y hasta su muerte los unió 
una estrecha amistad, los primeros años más caracterizada por las discusiones literarias, por las ideas estéticas y después del regreso de Nandino de Los Ángeles, ese acercamiento se tornó más "familiar", "[Villaurrutia] comía en mi casa todos los días. Y esto, por supuesto, se tiene que reflejar en el lenguaje, no sólo en las ideas. En algún texto, alguna vez, escribí una frase como: 'la anemia de los vidrios' y Xavier me dijo: 'Eso es mío'. Yo le contesté que no, que era una expresión médica; sólo así me pude defender” (Bustamante, 2009: 79).

En el estudio introductorio a la obra completa de Xavier Villaurrutia, Alí Chumacero señala tres etapas, "actitudes” le llama él, en la poesía del citadino. La primera está subyugada por el juego conceptual y formal de las palabras; en la segunda "su mejor época creadora, la emoción se somete a la estricta vigilancia de las facultades intelectuales, en un justo equilibrio que lo hizo escribir sus más hondos poemas" (Chumacero en Villaurrutia, 1966: XIV). La tercera “actitud”, la distinguirá, según Chumacero, el que "la emoción se sobrepon[ga] a la inteligencia con tal ímpetu, que la oblig[ue] a restringir su ejercicio sólo a la superficie de las formas métricas" (XIV). Es la segunda etapa la que interesa en este momento, la época de los nocturnos "cuando descubría que una idea maduraba con tal intimidad que no fuese el simple reflejo de algo objetivo, sino que se diera 'en función de vida y preocupación auténticas', palabras más o menos externaba Villaurrutia a José Luis Martínez (1940, 2: 75-76), entonces se iniciaba en el poeta la transfiguración de lo que comúnmente llamamos inspiración poética" (Chumacero en Villaurrutia, 1966: XIV). Esta es tal vez la obra que más se asemeje en ritmo, temática y forma a la de Nandino y constituye el conjunto de Nostalgia de la muerte. El de Nandino es un periodo de trabajo poético que abarca un amplio arco que se extiende por casi todo el siglo XX. Un largo río en ocasiones turbulento y otras manso. Una voz que fue madurando a golpes 
de constancia, como un orfebre al bruñir la pieza casi perfecta que acaba de salir de sus manos.

A Nandino le interesa el tono menor, no la grandilocuencia ni el pesado edificio de un pensamiento demasiado abstracto; o en todo caso es una abstracción que inmediatamente busca su concreción. Su poesía habla de emociones y de estados del ser; también de lo que le sucede al cuerpo que se mueve en este aquí y ahora terrenos, pero vinculados secretamente con el todo, en una conexión total con la Naturaleza. El cuerpo es en la Naturaleza, de manera tal que la muerte es un fin físico-biológico, pero es un renacer en el vientre más amplio del universo; el punto de comunión entre vida y muerte. Nandino está sensiblemente contagiado de todo lo que afecta a lo humano. Es muy humano.

[...]

cuando estoy a mi lado — centinela volátil—

como parte distinta de mi carne agobiada

y escucho los latidos del corazón: profundos

en mi forma tendida con quietud cadavérica;

[...]

cuando estoy a la orilla del dibujo desnudo

en que tomo apariencia

de estar vivo en la vida, y descubro que existo, entero y separado del corporal engrane donde sufro figura, [...]

Entonces siento el estelar espasmo

de una potencia en vilo,

el universo libre de mi lumbre pensante

en giro sin tropiezos por órbitas de ascenso,

[...]

Es entonces que palpo mi verdad liberada, el asueto espacial de mi cósmica almendra que comparte el dominio del empuje invencible 
del principio de todo y de todo en principio;

porque detrás de lo que no se toca,

de lo que nace y en la muerte acaba,

está lo que no puede cambiar, lo que es eterno

y parte indivisible

de la infinita evolución creadora:

es lo que queda vivo, sin nosotros,

y se suma de nuevo a la energía.

[...]

Porque después del cuerpo el hombre se trasvasa

al vaso sin paredes del espacio sin fondo,

para adquirir otra vez su ubicuidad perfecta

y el sideral oficio de donde fue robado

(Nandino, 1984: 22-24).

La noche es una "entraña” en Nandino, en la que nos sumergemos por el desliz del sueńo, por la curvatura sin forma del silencio nocturno. Nos colgamos de una escala descendente para llegar a esa "almendra" del mundo que nos contiene y a la que contenemos. Somos parte del universo en nuestro envoltorio corporal, carnal, biológico, pero más ontológicamente el poeta lo evidencia con un desdoblamiento en el cual la energía se desprende del cuerpo; aunque lo que en un principio se plantea como desasimiento, separación, deslinde se propondrá como reunión con lo primigenio universal. Hay aquí un transfondo, un rastro del naturalismo de Ralph Waldo Emerson, su idea de la vital force y por consiguiente del élan vital bergsoniano: "el hombre se trasvasa / al vaso sin paredes del espacio sin fondo, / para adquirir otra vez su ubicuidad perfecta”. Más que un cientificismo habría que leer en sus versos una conexión con el intuicionismo y la idea de contar de inmediato con un conocimiento de las cosas.

Cunndo por la escalera del silencio

bajamos a la noche de la entraña 
buscándonos, buscando

esa isla nostálgica, esa almendra

que sentimos atesorar muy hondo, más allá de confluencias de tejidos y follajes internos, y el descenso vendado por tinieblas se prolonga peldaño por peldaño, paso en pozo, desliz sin superficie, flotación en caída interminable, sin tropiezos, sin roces, sin memoria;

[...]

Y queremos llegar y no llegamos porque la entraña sigue, continúa, se vierte, se transmina, se dilata en polvo giratorio, en desbordada atmósfera de luto, en asustado tizne vagabundo, en espacio con rostro de obsidiana; y queremos llegar y no llegamos porque nace el abismo de otro abismo que conecta, se esparce, se difunde el cielo desastrado, éter desnudo, huyente inmensidad, lumbre de hielo, firmamento sin vísceras, ensanche creciente de la zona del desaire, [...]

¡Qué cerca de la muerte está la vida! [...]

La entraña de nosotros, nuestra entraña, llega hasta el Cosmos que no tiene entraña (Nandino, 1984: 32-33).

En el poema "Nocturna astronomía" queda muy a la intemperie su panteísmo, la pertenencia del hombre a la naturaleza. 
[...]

En la hondura flotante, sin orillas, que almendra la moldura en que vivimos, un sideral empuje nos germina en brote y en derrame indetenibles que al mismo tiempo, con la misma fuga, nos llena, nos deriva y nos escancia. [...]

El hombre es parte, síntesis y suma del misterio total que lo rodea y lo cubre, lo incubre y lo trasciende; es dinámica gota que se aúna al sistema solar de donde vino $\mathrm{y}$ al que tiende su mudo acercamiento; es nostálgico arranque involuntario que permanentemente se difunde hacia el imán eterno del origen. Medular, inasible, sin contorno, en un íntimo cerco de horizontes cada hombre aprisiona su universo y de su centro al exterior expande los milenios de luz de sus estrellas; y sólo se da cuenta de que existe su mundo sumergido, el cosmos suyo, cuando cierra los párpados y mira la oscuridad nocturna de su entraña que le muestra su oculta astronomía (Nandino, 1984: 45-47).

La referencia a la noche, al sueño, al silencio en Villaurrutia toma otros derroteros distintos a la filiación con los elementos naturales, con el cosmos. La poesía de Nandino se acerca más al canto, la piedra fundacional del poeta; y Villaurrutia sigue la estela del intelecto, sigue la huella imprecisa de Monsieur Teste y oye más el canto de la vanguardia con sus sirenas alucinadas por las imágenes 
sobrerrealistas que recuerdan los lienzos de Giorgio de Chirico, como en el "Nocturno de la estatua", recreación del Saisir, de Jules Supervielle, para reconvertirlo en una pintura digna de la Escuela metafísica.

Soñar, soñar la noche, la calle, la escalera y el grito de la estatua desdoblando la esquina.

Correr hacia la estatua y encontrar sólo el grito, querer tocar el grito y sólo hallar el eco, querer asir el eco y encontrar sólo el muro y correr hacia el muro y tocar un espejo. Hallar en el espejo la estatua asesinada, sacarla de la sangre de su sombra, vestirla en un cerrar de ojos, acariciarla como a una hermana imprevista y jugar con las fichas de sus dedos y contar a su oreja cien veces cien cien veces hasta oírla decir: "estoy muerta de sueño" (Villaurrutia, 1966: 46-47).

El de Xavier Villaurrutia es un estallamiento de los sentidos, pero celosamente vigilado por la luz de la conciencia, centinela que no dejaba al descuido su puesto ni por un minuto; un estallamiento, pero contrastadamente como el grito de una estatua. Es por eso que la idea que queda en el conjunto de poemas que integran Nostalgia de la muerte, aparecido como plaquette de diez nocturnos en la imprenta de Miguel N. Lira, en 1933, es la de la planificación y la estrategia, en el lenguaje y la forma, en las sinestesias y los juegos de aliteraciones, de espejos y paradojas. Hay mucho de artificio, de juegos pirotécnicos con el lenguaje en perfecta armonía con imágenes sorprendentes. Todo medido y puesto en sincronía, puesto para pensar, como una "rosa increada". 
La obra de Nandino y de Villaurrutia son puntos que se tocan en un vértice y se lanzan en fuga con direcciones opuestas. Parten de los mismos asuntos con tratamientos distintos, son las dos caras de la poesía, el Epimeteo y Prometeo perfilados en el Protágoras platónico, uno aborda el carro terrestre de la experiencia, el otro se desplaza sobre el carro de fuego de la inteligencia. Nandino se desliza en los vaivenes de la conciencia vital y Villaurrutia atiende los murmullos sutiles de la conciencia intelectual.

\section{Bibliografía}

Bustamante Bermúdez, Gerardo (sel., comp. y estudio), 2009, De dolores y placeres. Entrevistas con Elias Nandino entre 1954 y 1993, México, Gobierno del Distrito Federal / Universidad Autónoma de la Ciudad de México.

Chumacero, Alí, 1966, "Prólogo" a Xavier Villaurrutia, Obras, México, FCE.

Forster, Merlin H., 1964, Los Contemporáneos 1920-32. Perfil de un experimento vanguardista mexicano, México, Ediciones de Andrea.

López Velarde, Ramón, 1986, Obras, México, FCE.

Martínez, José Luis, 1990, Literatura mexicana siglo XX. 19101949, México, Conaculta.

, 1940, "Con Xavier Villaurrutia" (entrevista), Tierra Nueva, año I, núm. 2, marzo-abril, México, pp. 74-81.

Nandino, Elías, 2000, Juntando mis pasos, México, Aldus. , 1982, Nocturna suma, México, Katún. , 1984, "Nocturna evasión”, en Nocturna palabra, México, Domés, pp. 22-24. 
, 1984, "Nocturno descenso", en Nocturna palabra, México, Domés, pp. 32-33.

, 1984, "Nocturna astronomía", en Nocturna palabra, México, Domés, pp. 45-47.

Sheridan, Guillermo, 2003, Los Contemporáneos ayer, México, FCE.

Schneider, Luis Mario (ed. y recop.), 1981, Jorge Cuesta. Poemas, ensayos y testimonios, t. V, México, UNAM.

Paz, Octavio, 2003, Xavier Villaurrutia en persona y en obra, México, FCE.

Owen, Gilberto, Obras, Josefina Procopio (ed.), Alí Chumacero (pról.), Josefina Procopio, Miguel Capistrán, Luis Mario Schneider e Inés Arredondo (recop.), México, FCE.

Villaurrutia, Xavier, 2003, "Carta a un joven (Edmundo Valadés)", en Guillermo Sheridan, Los Contemporáneos ayer, México, FCE, p. 166.

, 1966, Obras, Alí Chumacero (pról.), Miguel Capistrán, Alí Chumacero y Luis Mario Schneider (recop.), Luis Mario Schneider (biblio.), México, FCE.

, 1982, "Prólogo" a Ecos, México, Katún, pp. 7-9. 